\title{
Direct Laryngoscopy with Biopsy
}

National Cancer Institute

\section{Source}

National Cancer Institute. Direct Laryngoscopy with Biopsy. NCI Thesaurus. Code C51659.

Removal of laryngeal tissue under direct visualization for microscopic examination. 